\title{
Changes in transthoracic electrical impedance at high altitude
}

\author{
RAGHUNATH SINGH HOON, V. BALASUBRAMANIAN, \\ SURESH C. TIWARI, OOMMAN P. MATHEW, ARUN BEHL, \\ SUBHASH CHANDER SHARMA, AND KANWAR S. CHADHA
}

From the Directorate General, Armed Forces Medical Services, Ministry of Defence, ' $M$ ' Block, New Delhi, 110001, India

\begin{abstract}
Mean transthoracic electrical impedance (impedance) which is inversely related to intrathoracic extravascular fluid volume was measured in 121 normal healthy volunteers at sea-level and at 3658 metres altitude. Fifty (group $A$ ) reached the high altitude location after an hour's journey in a pressurised aircraft. Twentyfive (group D) underwent slow road ascent including acclimatisation en route. Thirty permanent residents (group B) and 16 temporary residents at high altitude (group C) were also studied. Serial studies in the 30 subjects of group $A$ who developed symptoms of high altitude sickness showed a significant decrease of impedance up to the fourth day of exposure to high altitude which later returned to normal. The 4 volunteers who developed severe symptoms showed the largest drop in impedance. A case of acute pulmonary oedema developing at 4300 metres showed an impedance value of $24 \cdot 1 \mathrm{ohms}$ on admission. After effective treatment the impedance increased by 11.9 to 36.0 ohms. Twenty asymptomatic subjects of group $A$ and 25 of group $D$ showed a small average increase in impedance values at high altitude. These observations suggest that measurement of transthoracic electrical impedance may be a valuable means of detecting incipient high altitude pulmonary.oedema.
\end{abstract}

Important physiological changes are known to occur in the human cardiorespiratory system on exposure to high altitude (Hultgren and Grover, 1968; Roy et al., 1968a; Balasubramanian et al., 1975). One of the most serious consequences of such exposure is acute pulmonary oedema, which may be fatal (Fred et al., 1962; Menon, 1965; Singh, 1965; Singh et al., 1965, 1969; Penalozo and Sime, 1969). This problem is of great importance to troops deployed at high altitudes and to trekkers or mountaineers exploring extreme heights. The prophylaxis, early detection, and treatment of high altitude pulmonary oedema have, therefore, been the subject of intensive research in recent years (Roy et al., 1968a; Bhatia et al., 1969; Roy et al., 1974).

Changes in mean transthoracic electrical impedance have been reported to reflect alterations in pulmonary extravascular fluid volume (Pomerantz et al., 1969; Pomerantz et al., 1970; Berman et al., 1971; Van de Water et al., 1973; Luepker et al., 1973; Balasubramanian and Hoon, 1975, 1976). The impedance technique, being totally noninvasive

Received for publication 3 June 1976 and easy to perform, holds considerable promise in the early detection of pulmonary oedema.

A controlled study was undertaken to estimate serial changes in the mean transthoracic electrical impedance of normal subjects on exposure to high altitude and on return to sea-level. For comparison groups of permanent and temporary residents at high altitude were also studied.

\section{Subjects and method}

Studies were made on 121 normal, healthy, male volunteers 21 to 35 years of age who were divided into four groups.

Group $A: 50$ subjects normally resident at altitudes lower than 1000 metres (lowlanders). They had never been exposed to higher altitudes before the sudden ascent by air to 3658 metres.

Group $B: 30$ 'highlanders' born and brought up at altitudes above 3000 metres. They were permanent residents of these areas and had never been to lower altitudes.

Group C: 16 'lowlanders' who had spent 120 to 180 days continuously at an altitude of 3658 metres immediately preceding the study. 
Group D: 25 'lowlanders' exposed to 3658 metres after slow ascent by road and acclimatisation en route.

All the four groups were comparable in anthropometric measurements and physical training. All investigations were made in the supine position between 9 and 11 am, 3 hours after light breakfast, except for some of the studies in group A soon after arrival at high altitude. Each subject was made to rest for a minimum of 30 minutes to arrive at a basal state before the recording procedure. The same electrodes, electrolyte jelly, and impedance plethysmograph were used throughout the study. The plethysmograph was tested and found to be stable at up to 5000 metres altitude and within a temperature range of $10^{\circ} \mathrm{C}$ to $50^{\circ} \mathrm{C}$. The accuracy was further tested before each measurement by introducing a precision $26.0 \mathrm{ohm}$ resistor into the circuit.

SERIAL STUDY OF GROUP A

The 50 subjects of group A were initially studied at a laboratory 198 metres above sea-level (henceforth called sea-level) on 2 consecutive days. The mean was accepted as the basal control value. They were then airlifted to an altitude of 3658 metres in 55 minutes by a pressurised aircraft. The first recording at high altitude started within 30 minutes of arrival. Twenty-five subjects were studied within 4 hours of their arrival. All the 50 were restudied at 5 to 8 hours and on the second, third, fourth, fifth, and tenth day of arrival at high altitude. They were then brought back to sea-level by air and the studies repeated within 4 hours of arrival and on the second and third day of return.

GROUPS B AND C

These volunteers were studied once at high altitude.

\section{GROUP D}

After initial study at sea-level, these subjects reached an altitude of 1800 metres in 60 hours by rail/road travel. They were then taken to an altitude of 2800 metres by road and underwent acclimatisation lasting 8 days. Finally they travelled by road to 3658 metres in 50 hours. They were here restudied on the first, second, third, fourth, fifth, and tenth day of arrival. Subsequent studies, as for group A, were carried out after bringing them back to sealevel by air.

During the stay at high altitude relevant symptoms were recorded on a scored chart. Arbitrary scores were assigned to the important symptoms. Heaviness of chest, moist cough, mucoid expectoration, dyspnoea on moderate exertion, anorexia, nausea, vomiting, and headache were assigned 1 mark each. Dyspnoea on mild exertion was given 2 marks, dyspnoea at rest 3 marks, and pink frothy sputum 5 marks, respectively. On this basis cases of pulmonary oedema attained a score of 10 or more and those with the usual side effects of high altitude induction 4 or less. Subjects with scores 5 or above were classified as 'symptomatic' and those who scored 4 or less 'asymptomatic'.

\section{TRANSTHORACIC ELECTRICAL IMPEDANCE (IMPEDANCE) MEASUREMENT}

The instrument used was an automatic balancing digital impedance plethysmograph consisting basically of a $20 \mathrm{kHz}$ oscillator exciting a constant current source of $200 \mu \mathrm{A}$. Two pairs of silver-coated copper mesh strips of $5 \mathrm{~mm}$ width were used as the tetrapolar circular lead system (Fig.). A constant sinusoidal $20 \mathrm{kHz}$ alternating current of $200 \mu \mathrm{A}$ RMS was passed between the two outer electrodes E1 and E4. The inner electrodes E2 and E3 permitted the detection of the drop in the voltage of the signal across the chest using a high impedance voltmeter (with an accuracy of $\pm 0.1 \mathrm{ohm}$ ).

The two electrode pairs were bonded to a neoprene belt at a distance of $5 \mathrm{~cm}$ to ensure uniformity of electrode distance. The neck electrodes (E1 and E2) were thus $5 \mathrm{~cm}$ apart just above and below the cricoid cartilage. The thoracic electrodes (E3 and E4) were placed at the xiphisternum and $5 \mathrm{~cm}$ distal to it. The electrode locations were carefully marked with indelible ink during the first study to ensure electrode placements at the same sites in successive estimations. The impedance was measured at end-expiration, with the subject breathing normally.

The data were analysed by an ICL 1904 computer. The statistical significance was obtained by Student's $\mathrm{t}$ and $\chi^{2}$ tests.

\section{Results}

Of the 50 subjects in group A, 30 scored 5 or more marks at high altitude and were graded 'symptomatic'. The other 20 scored less than 4 and were classified 'asymptomatic'. None of the 25 subjects of group D who reached high altitude by road after acclimatisation en route had scores above 4 nor did they develop significant symptoms.

SYMPTOMATIC SUBJECTS GROUP A

The mean baseline impedance was $26 \cdot 7 \pm 2.0 \mathrm{ohms}$ (range 21.6 to $30.1 \mathrm{ohms}$ ). The variation in the same individual during the initial 2 estimations at sealevel was only $\pm 0.5 \mathrm{ohm}$. The impedance response to high altitude exposure in this group is shown in Table 1. The levels of significance between the different groups and subgroups are also shown in Table 1. Immediately on arrival at high altitude these subjects showed an $\mathbf{8 . 4}$ per cent increase in 


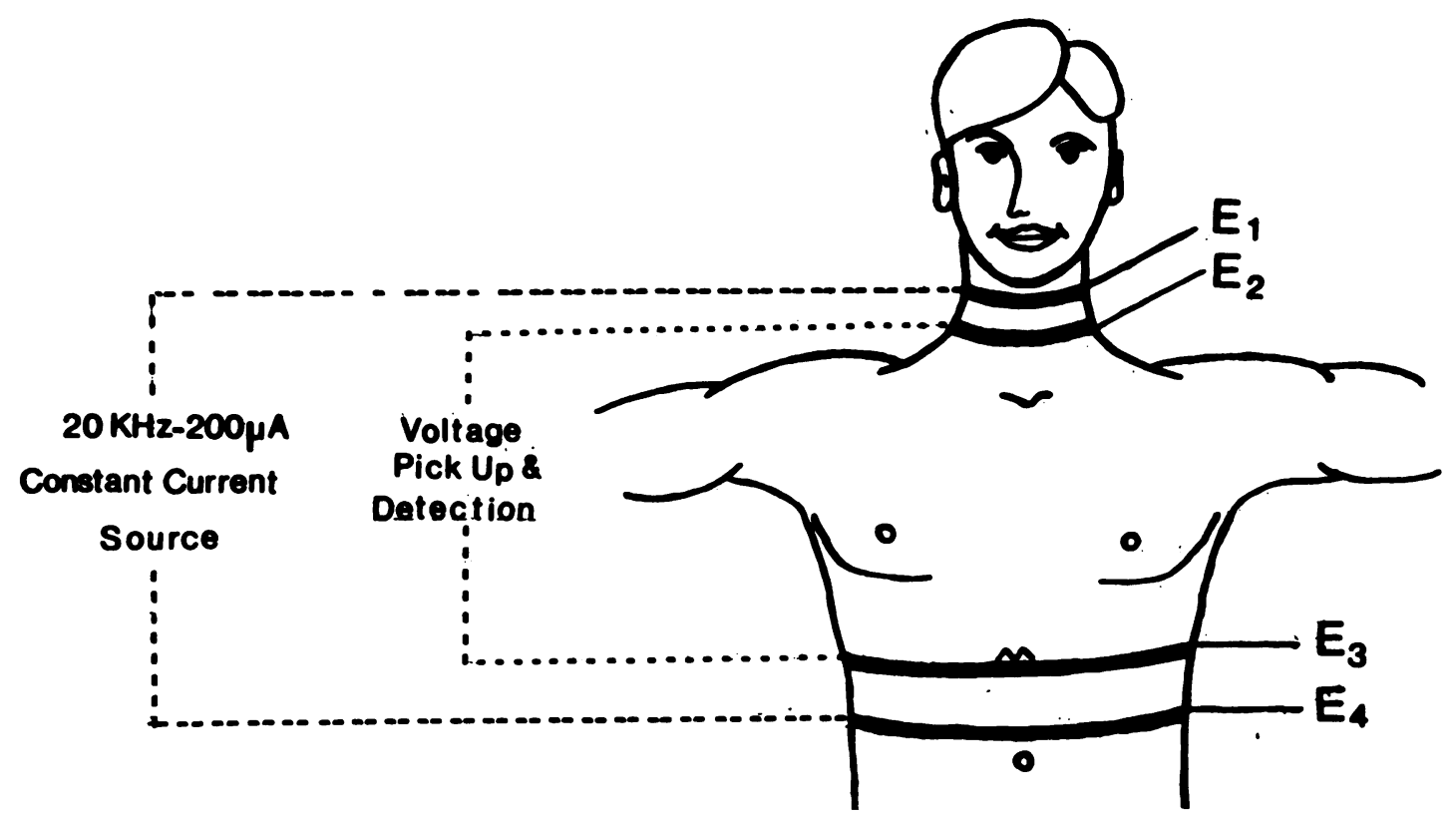

Fig. Electrode placement for transthoracic electrical impedance measurement.

Table 1 Alterations in impedance of 50 subjects inducted by air to high altitude

\begin{tabular}{|c|c|c|c|c|c|c|c|c|}
\hline & \multicolumn{2}{|c|}{ Symptomatic group $A$} & \multicolumn{2}{|c|}{ Asymptomatic group $A$} & \multirow[t]{2}{*}{$P_{\mathrm{a}}$} & \multirow[t]{2}{*}{$P_{\mathrm{b}}$} & \multirow[t]{2}{*}{$P_{\mathrm{c}}$} & \multirow[t]{2}{*}{$P_{\mathrm{d}^{*}}$} \\
\hline & $\begin{array}{l}\text { Mean } \\
\text { impedance } \\
\text { (ohms) }\end{array}$ & $\begin{array}{l}\text { Impedance as } \\
\text { percentage } \\
\text { of sea-level }\end{array}$ & $\begin{array}{l}\text { Mean } \\
\text { impedance } \\
\text { (ohms) }\end{array}$ & $\begin{array}{l}\text { Impedance as } \\
\text { percentage } \\
\text { of sea-level }\end{array}$ & & & & \\
\hline Sea-level & $\begin{array}{l}26 \cdot 7 \\
(2 \cdot 0)\end{array}$ & $\begin{array}{c}100 \cdot 0 \\
(0 \cdot 0)\end{array}$ & $\begin{array}{l}25 \cdot 3 \\
(2 \cdot 3)\end{array}$ & $\begin{array}{c}100 \cdot 0 \\
(0 \cdot 0)\end{array}$ & - & NS & NS & NS \\
\hline \multicolumn{4}{|c|}{$\begin{array}{l}\text { Induction to high altitude } \\
0 \text { to } 4 \text { hours }\end{array}$} & $111 \cdot 7$ & $<0.01$ & NS & NS & NS \\
\hline 5 to 8 hours & $\begin{array}{l}(2 \cdot 2) \\
26 \cdot 0 \\
(2 \cdot 4)\end{array}$ & $\begin{array}{l}(7 \cdot 8) \\
96 \cdot 0 \\
(6 \cdot 4)\end{array}$ & $\begin{array}{l}(1 \cdot 5) \\
26 \cdot 5 \\
(2 \cdot 1)\end{array}$ & $\begin{array}{c}(8 \cdot 0) \\
104 \cdot 7 \\
(7 \cdot 0)\end{array}$ & $<0.01$ & NS & NS & $<0.001$ \\
\hline 2nd day & $\begin{array}{l}25.9 \\
(2.6)\end{array}$ & $\begin{array}{c}95 \cdot 3 \\
(11 \cdot 5)\end{array}$ & $\begin{array}{l}26 \cdot 4 \\
(2 \cdot 8)\end{array}$ & $\begin{array}{c}104 \cdot 1 \\
(8 \cdot 6)\end{array}$ & $<0.01$ & NS & $<0.01$ & $<0.01$ \\
\hline 3rd day & $\begin{array}{l}25 \cdot 4 \\
(2 \cdot 7)\end{array}$ & $\begin{array}{l}95 \cdot 1 \\
(9 \cdot 6)\end{array}$ & $\begin{array}{l}26.4 \\
(1 \cdot 8)\end{array}$ & $\begin{array}{r}105 \cdot 1 \\
(6 \cdot 5)\end{array}$ & $<0.01$ & $<0.001$ & $<0.01$ & $<0.001$ \\
\hline 4th day & $\begin{array}{l}25 \cdot 4 \\
(2 \cdot 3)\end{array}$ & $\begin{array}{l}95 \cdot 1 \\
(9 \cdot 6)\end{array}$ & $\begin{array}{l}26.8 \\
(1.8)\end{array}$ & $\begin{array}{r}106 \cdot 0 \\
(6 \cdot 4)\end{array}$ & $<0.01$ & $<0.001$ & $<0.01$ & $<0.001$ \\
\hline 5th day & $\begin{array}{l}26 \cdot 5 \\
(3 \cdot 2)\end{array}$ & $\begin{array}{c}98.9 \\
(14.9)\end{array}$ & $\begin{array}{l}27 \cdot 0 \\
(1 \cdot 8)\end{array}$ & $\begin{array}{c}107 \cdot 2 \\
(7 \cdot 1)\end{array}$ & NS & NS & NS & $<0.01$ \\
\hline 10th day & $\begin{array}{l}27 \cdot 3 \\
(3 \cdot 5)\end{array}$ & $\begin{array}{l}101 \cdot 7 \\
(9 \cdot 7)\end{array}$ & $\begin{array}{l}27 \cdot 7 \\
(1 \cdot 6)\end{array}$ & $\begin{array}{c}108 \cdot 0 \\
(7 \cdot 0)\end{array}$ & NS & NS & NS & $<0.01$ \\
\hline $\begin{array}{l}\text { Return to sea-level } \\
\text { Ist day }\end{array}$ & $\begin{array}{l}26 \cdot 2 \\
(2 \cdot 5)\end{array}$ & $\begin{array}{l}99 \cdot 7 \\
(8 \cdot 7)\end{array}$ & $\begin{array}{l}26 \cdot 5 \\
(1 \cdot 7)\end{array}$ & $\begin{array}{l}105 \cdot 1 \\
(11 \cdot 0)\end{array}$ & NS & NS & NS & NS \\
\hline 2nd day & $\begin{array}{l}26 \cdot 8 \\
(2 \cdot 1)\end{array}$ & $\begin{array}{r}100 \cdot 2 \\
(9 \cdot 7)\end{array}$ & $\begin{array}{l}26 \cdot 2 \\
(1 \cdot 8)\end{array}$ & $\begin{array}{c}103 \cdot 2 \\
(9 \cdot 5)\end{array}$ & NS & NS & NS & NS \\
\hline 3rd day & $\begin{array}{l}26 \cdot 8 \\
(2 \cdot 1)\end{array}$ & $\begin{array}{c}100 \cdot 2 \\
(8 \cdot 7)\end{array}$ & $\begin{array}{l}26 \cdot 0 \\
(2 \cdot 5)\end{array}$ & $\begin{array}{c}101 \cdot 4 \\
(9 \cdot 8)\end{array}$ & NS & NS & NS & NS \\
\hline Group B & $\begin{array}{l}27 \cdot 1 \\
(2 \cdot 3)\end{array}$ & & & & & & & \\
\hline Group C & $\begin{array}{l}28 \cdot 1 \\
(2 \cdot 4)\end{array}$ & & & & & & & \\
\hline
\end{tabular}

Group $B=$ permanent residents of high altitude; group $C=$ temporary residents of high altitude; $P_{\mathrm{a}}=$ comparison of symptomatic subjects with sea level values; $P_{b}=$ comparison of symptomatic subjects with group $B ; P_{c}=$ comparison of symptomatic subjects with group $C$; $P_{d}=$ comparison of symptomatic with asymptomatic subjects.

Figures in parentheses indicate standard deviation.

$\star$ Statistical significance derived from percentage alterations as compared with sea-level value. 
impedance values $(P<0.01)$ when compared with their sea-level figures. From 5 to 8 hours onwards, however, there was a significant reduction in impedance levels in the symptomatic subjects of group A when compared with their sea-level control values $(P<0.01)$ and with all the other groups up to the fourth day of arrival at high altitude $(P<0.001)$. The fifth and tenth day readings were, however, not significantly different from the control figures.

It was found that a significantly larger number of subjects in the symptomatic group developed a drop in the impedance values as compared with the asymptomatic subjects up to day 4 at high altitude $(\mathrm{P}<0.01)$. Altogether, 26 out of 30 in the symptomatic group showed a drop of $1.5 \mathrm{ohms}$ on any one day and the other 4 showed a drop of 1.0 to 1.4 ohms. Of these 30 subjects, 4 developed severe breathlessness at rest, dry cough, heaviness in the chest, moist sounds in both lungs, headache, malaise, and radiological changes suggesting incipient pulmonary oedema. They showed gross reduction in impedance levels, i.e. $-6 \cdot 6,-4 \cdot 9,-4 \cdot 5$, and $-5.2 \mathrm{ohms}$, respectively, at the height of symptoms. When the symptoms improved the impedance values returned to normal levels.

\section{ASYMPTOMATIC SUBJECTS}

\section{Group $A$}

The impedance response of the asymptomatic group was different from that of the symptomatic group (Table 1). Immediately on arrival at high altitude, the impedance increased by 11.7 per cent as compared with 8.4 per cent in the symptomatic group. At 5 to 8 hours there was a reduction of 7.0 per cent from these values, but the mean impedance was still higher than the sea-level values by 4.7 per cent. On subsequent days no decrease in impedance was observed. On the other hand, a mild

Table 2 Alterations in impedance of 25 subjects who reached 3658 metres altitude by road after gradual acclimatisation en route

\begin{tabular}{llll}
\hline & $\begin{array}{l}\text { Mean } \\
\text { impedance } \\
\text { (ohms) }\end{array}$ & $S D$ & $P$ \\
\hline Sea-level & 25.9 & $2 \cdot 2$ & \\
$\begin{array}{l}\text { High altitude } \\
\text { 1st day }\end{array}$ & 26.4 & $2 \cdot 2$ & NS \\
2nd day & 26.6 & $2 \cdot 1$ & NS \\
3rd day & 26.1 & $1 \cdot 9$ & NS \\
4th day & 26.2 & $1 \cdot 8$ & NS \\
5th day & 26.3 & $2 \cdot 1$ & NS \\
10th day & 26.6 & $1 \cdot 7$ & $<0.01$ \\
Return to sea-level & 26.3 & 1.7 & NS \\
1st day & 26.0 & $2 \cdot 1$ & NS \\
2nd day & 25.3 & 1.9 & NS \\
3rd day & 25 & \\
\hline
\end{tabular}

$\mathbf{P}=$ Compared with sea-level values. increase ranging from 4.1 to 8.0 per cent was noticed when compared with the sea-level values. This increase in impedance returned to normal on the third day of return to sea-level. The increase in impedance was statistically significant $(P<0.01)$ at 0 to 4 hours, fifth and tenth days at high altitude.

\section{Group D (Table 2)}

None of the 25 subjects who were exposed to high altitude at 3658 metres after acclimatisation en route developed significant symptoms and all of them scored less than 4 marks. Their impedance response was similar to the asymptomatic subjects of group A. There was a mild increase of mean impedance from 25.9 to $26.6 \mathrm{ohms}$ up to the tenth day of stay at high altitude which returned to normal at sea-level. None of these subjects developed a decrease of impedance more than $1.5 \mathrm{ohms}$ during their stay at high altitude. Statistically no difference was discernible between this group and asymptomatic subjects of group A.

\section{Groups $B$ and $C$}

The permanent residents of high altitude (group B) and the temporary residents of high altitude (group C) showed a range of impedance values simplar to group D and the asymptomatic subjects of group A.

\section{Case reports}

\section{CASE 1}

A 26-year-old male volunteer for this study had an impedance value of $28.0 \mathrm{ohms}$ at sea-level. On arrival at 3658 metres the value was $26.4 \mathrm{ohms}$ up to the second day. On the third day he complained of malaise, headache, unproductive cough, and breathlessness at rest. His impedance had by now dropped to $23.3 \mathrm{ohms}$. A chest $x$-ray showed prominent pulmonary vasculature. $\mathrm{He}$ was treated with strict bed rest and oxygen inhalations. He showed subjective improvement and the impedance increased to $25.9 \mathrm{ohms}$ in 24 hours. Treatment was discontinued to see the effect. The symptoms recurred and the impedance fell by $6.6 \mathrm{ohms}$ from the control values. Oxygen was started again and within 24 hours the clinical state returned to normal and the impedance reached $27.5 \mathrm{ohms}$. Subsequently he remained normal, with impedance values of 27.0 and $27 \cdot 8 \mathrm{ohms}$, respectively.

CASE 2

During the study a 26-year-old soldier was brought to the altitude laboratory with severe dyspnoea at rest, headache, and productive cough of acute onset occurring at an altitude of 4300 metres. The clinical findings and radiological features were 
classical of acute high altitude pulmonary oedema. His thoracic impedance was found to be $24 \cdot 1 \mathrm{ohms}$. Under constant impedance monitoring he was given 8 litres of oxygen/min by a B.L.B. mask and a combination of $40 \mathrm{mg}$ frusemide and $15 \mathrm{mg}$ morphine intravenously. There was no change in the impedance values or clinical picture during the first 2 hours. The patient did not have any diuresis. A second dose of $80 \mathrm{mg}$ frusemide was given. This evoked brisk diuresis, associated with pronounced clinical improvement, within 30 minutes. The impedance at this stage was $26.7 \mathrm{ohms}$. It reached $29 \cdot 1 \mathrm{ohms}$ within the next two hours. The following day when the patient was completely asymptomatic the value was $36 \cdot 3 \mathrm{ohms}$. On discharge 15 days later the impedance was $36.0 \mathrm{ohms}$ confirming that his normal level was $36.0 \mathrm{ohms}$ and that the pulmonary oedema had been associated with a drop of $11.9 \mathrm{ohms}$. This case illustrates the value of continuous impedance monitoring for assessing the response to treatment in acute pulmonary oedema of high altitude. It also highlights the necessity for repeated observation.

\section{Discussion}

Transthoracic electrical impedance estimations have been extensively used for noninvasive monitoring of thoracic fluid volume changes by a number of workers in different clinical settings (Berman et al., 1971; Van de Water et al., 1973; Balasubramanian et al., 1975; Balasubramanian and Hoon, 1976). Pomerantz et al. (1969) reported that a decrease in impedance occurred much earlier than changes in blood gases, blood pressure, central venous pressure, or pulmonary compliance in experimental pulmonary oedema in dogs. In a similar study Berman and coworkers (1971) found that changes in impedance reflected volume changes in pulmonary oedema more faithfully than central venous pressure. Luepker and associates (1973) reported a series of elegantly controlled studies of central blood volume, pulmonary extravascular volume, and transthoracic electrical impedance in dogs. They found that thoracic impedance was a reliable index of pulmonary oedema, correlating well with the rise in central blood volume and pulmonary extravascular fluid volume and was more sensitive than either of these. They also showed that impedance alterations were more dependent on pulmonary extravascular fluid volume rather than on central blood volume. This was attributed to the greater resistivity of whole blood compared to that of serum. Van de Water et al. (1973) reported a number of cases where impedance studies were useful indications of increasing intrathoracic fluid. From these studies it appeared that measurement of impedance changes is a reliable indicator of pulmonary oedema.

In the present study 50 normal volunteers were studied on 2 successive days at sea-level and their impedance values did not vary by more than $\pm 0.5 \mathrm{ohms}$. On exposure to high altitude, the changes followed two distinct patterns. The asymptomatic group showed a mild but significant increase in impedance which reached a peak on the tenth day of stay at high altitude and returned to normal at sea-level. Similar changes were observed in the group who reached high altitude after gradual acclimatisation en route.

The symptomatic group on the other hand showed a significant drop in the impedance values which reached a minimum on the third and fourth days of arrival at high altitude. It is noteworthy that these are the days when the incidence of pulmonary oedema is the highest and the pulmonary blood volume maximal (Roy et al., 1968a).

The levels then increased and became normal by the tenth day when all subjects became symptom free. This trend is consistent with the contention that impedance changes reflect alterations in pulmonary extravascular fluid volume accurately and can help in the early detection of pulmonary oedema. The pronounced drop in impedance observed in the 4 subjects with severe high altitude illness and the return to normal once they became asymptomatic further supports this correlation. In a preliminary pilot study Roy et al. (1974) estimated the impedance by an analogue impedance plethysmograph in 20 normal subjects at sea-level. These subjects were taken to high altitude by air and the serial studies were performed after 24 hours in 10 subjects, 48 hours in 12 subjects, and third to tenth day in 18 subjects. They reported a baseline value of $34.6 \pm 0.6 \mathrm{ohms}$ at sea-level with a pronounced reduction at high altitude in all their subjects. Five patients with acute mountain sickness and high altitude pulmonary oedema were also simultaneously studied and found to have low impedance values (Balasubramanian et al., 1974; Roy et al., 1974).

The current study was planned to delineate the impedance response in a large number of subjects when exposed to high altitude. The research team reached high altitude earlier than the volunteers to study the impedance response immediately on arrival. This was essential to define a second baseline level at high altitude as no similar studies have so far been reported. We found a significant increase in impedance up to 4 hours after landing which could be explained by the physiological increase in the volume of intrathoracic air occurring at high altitude. It has been documented that im- 
pedance increases with increase in intrathoracic air. Luepker and coworkers (1973) reported an increase in impedance with positive pressure ventilation and pneumothorax. Balasubramanian and Hoon (1976) found that hyperventilation increased the impedance by $0.6 \mathrm{ohms}$ in 20 normal subjects. The mean baseline impedance level in this study was $25 \cdot 7$ to $26.7 \mathrm{ohms}$, which is in agreement with the figures of $25 \pm 5.0 \mathrm{ohms}$ reported by a number of workers.

By contrast the significance of the selective fall of impedance in symptomatic subjects is obvious, and suggests that it may be possible to detect cases of high altitude pulmonary oedema in the incipient stage, with the aid of serial impedance estimations. It has been reported that a significant fall in impedance is virtually always of clinical importance (Van de Water et al., 1973).

There is a real need for a reliable, rapid, and noninvasive method for detection of acute pulmonary oedema of high altitude. The disease is prevalent in mountainous terrain with a hostile environment where facilities for sophisticated invasive haemodynamic studies and reliable radiological investigations may not be readily available. The disorder may present in an acute form with dramatic symptoms and can be rapidly fatal if not treated early enough. Impedance studies merit further detailed investigations to determine their value in this situation. In our limited experience they appear to be promising.

It should be noted that a single impedance estimation may be misleading. Serial estimations should be carried out to establish the diagnosis and assess progress. This point was well brought out in the second case reported above. Measurements of changes in transthoracic electrical impedance provide a simple, reliable, and noninvasive method for early detection and follow-up of cases of high altitude pulmonary oedema. It must however be appreciated that impedance cannot separate the effects of intravascular or extravascular fluid shifts quantitatively, even though the changes are influenced to a greater extent by changes in pulmonary extravascular volume (Luepker et al., 1973). Thus a drop in impedance can serve to alert the physician to look for a change in the thoracic fluid volume but it does not quantify this change.

The authors are grateful to Brigadier Sundaram and Major Sarbjit Singh of Army Headquarters Electronic Data Processing Centre, New Delhi, India, for computing assistance, and the Armed Forces Medical Research Committee for financial support.

\section{References}

Balasubramanian, V., and Hoon, R. S. (1975). Clinical applications of transthoracic electrical impedance. Fournal of the Association of Physicians of India, 23, 611.

Balasubramanian, V., and Hoon, R. S. (1976). Changes in transthoracic electrical impedance during submaximal treadmill exercise in patients with ischemic heart disease: a preliminary report. American Heart fournal, 91, 43.

Balasubramanian, V., Kaushik, V. S., Manchanda, S. C., and Roy, S. B. (1975). Effects of high altitude hypoxia on left ventricular systolic time intervals in man. British Heart fournal, 37, 272.

Balasubramanian, V., Khan, M. R., Guha, S. K., and Roy, S. B. (1974). Changes in transthoracic electrical impedance of patients with high altitude pulmonary oedema and acute mountain sickness. In Proceedings of 4th All India Symposium on Biomedical Engineering, p. 321. All India Institute of Technology, New Delhi.

Berman, I. R., Scheetz, W. L., Jenkins, E. B., and Hufnagel, H. V. (1971). Transthoracic electrical impedance as a guide to intravascular overload. Archives of Surgery, 102, 61.

Bhatia, M. L., Singh, I., Manchanda, S. C., Khanna, P. K., and Roy, S. B. (1969). Effect of frusemide on pulmonary blood volume. British Medical fournal, 2, 551.

Fred, H. L., Schmidt, A. M., Bates, T., and Hecht, H. H. (1962). Acute pulmonary edema of altitude; clinical and physiologic observations. Circulation, 25, 929.

Hultgren, H. N., and Grover, R. F. (1968). Circulatory adaptation to high altitude. Annual Review of Medicine, $19,119$.

Luepker, R. V., Michael, J. R., and Warbasse, J. R. (1973). Transthoracic electrical impedance: quantitative evaluation of a non-invasive measure of thoracic fluid volume. American Heart fournal, 85, 83.

Menon, N. D. (1965). High-altitude pulmonary edema. New England fournal of Medicine, 273, 66.

Penaloza, D. and Sime, F. (1969). Circulatory dynamics during high altitude pulmonary edema. American fournal of Cardiology, 23, 369.

Pomerantz, M., Baumgartner, R., Lauridson, J., and Eiseman, B. (1969). Transthoracic electrical impedance for the early detection of pulmonary edema. Surgery, 66, 260.

Pomerantz, M., Delgado, F., and Eiseman, B. (1970). Clinical evaluation of transthoracic electrical impedance as a guide to intrathoracic fluid volumes. Annals of Surgery, 171, 686.

Roy, S. B., Balasubramanian, V., Khan, M. R., Kaushik, V. S., Manchanda, S. C., and Guha, S. K. (1974). Transthoracic electrical impedance in cases of high-altitude hypoxia. British Medical fournal, 3, 771.

Roy, S. B., Guleria, J. S., Khanna, P. K., and Manchanda, S. C. (1968a). Pulmonary blood-volume in high-altitude pulmonary oedema. (Letter.) Lancet, 1, 388.

Roy, S. B., Guleria, J. S., Khanna, P. K., Talwar, J. R., Manchanda, S. C., Pande, J. N., Kaushik, V. S., Subba, P. S., and Wood, J. E. (1968b). Immediate circulatory reponse to high altitude hypoxia in man. Nature, 217, $\$ 177$.

Singh, I. (1965). High-altitude pulmonary edema. American Heart fournal, 70, 435.

Singh, I., Kapila, C. C., Khanna, P. K., Nanda, R. B., and Rao, B. D. P. (1965). High-altitude pulmonary oedema. Lancet, 1, 229.

Singh, I., Khanna, P. K., Srivastava, M. C., Lal, M., Roy, S. B., and Subramanayam, C. S. V. (1969). Acute mountain sickness. New England Fournal of Medicine, 280, 175.

Van de Water, J. M., Mount, B. E., Barela, J. R., Schuster, R., and Leacock, F. S. (1973). Monitoring the chest with impedance. Chest, 64, 597.

Requests for reprints to Lieut. General R. S. Hoon, Director General, Armed Forces Medical Services, Ministry of Defence, ' $M$ ' Block, New Delhi 110001, India. 